Recorregut de recerca geològica i geoambiental per la comarca de l'Anoia: des d'Igualada a la Serra de Rubió, Sant Martí de Maçana, la Manresana i als Prats de Rei

Josep Maria Mata-Perelló

Joaquim Sanz Balagué

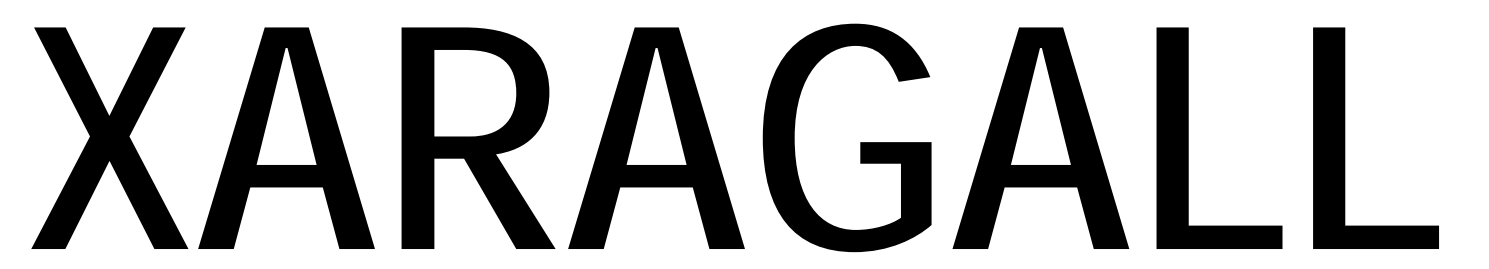

REVSTA DE CIÈNCIES DE LA CATALUUNYA CENIRAL n. 12

DESEMBRE 2014 


\title{
RECORREGUT DE RECERCA GEOLÒGICA I GEOAMBIENTAL PER LA COMARCA DE L'ANOIA: DES D'IGUALADA A LA SERRA DE RUBIÓ, SANT MARTÍ DE MAÇANA, LA MANRESANA I ALS PRATS DE REI
}

\author{
Josep Maria Mata-Perelló \\ Museu de geologia Valentí Masachs, Escola Politècnica Superior d'Enginyeria de Manresa \\ (EPSEM), Universitat Politècnica de Catalunya · BarcelonaTech (UPC), 08272 Manresa, Spain
}

\section{Joaquim Sanz Balagué}

Departament d'Enginyeria Minera i Recursos Naturals (EMRN), Escola Politècnica Superior d'Enginyeria de Manresa (EPSEM), Universitat Politècnica de Catalunya . BarcelonaTech (UPC), 08272 Manresa, Spain

Paraules clau: Depressió Geològica de l'Ebre, Materials terciaris, Materials quaternaris, Patrimoni miner

\section{Resum}

Itinerari realitzat el 25 de gener de 2014. En aquesta ocasió, es realitzarà un recorregut geològic que discorrerà en la seva totalitat per diferents indrets de la Depressió Geològica de I'Ebre; i més concretament pels sectors corresponents a la seva Depressió Central. D'aquesta manera, tot el recorregut transitarà entre afloraments dels materials terciaris (de l'Eocè i de I'Oligocè) i quaternaris que reblen aquesta depressió.

Per d'altra banda, la totalitat del recorregut transitarà per la comarca de l'Anoia, integrant de la Catalunya Central, de principi a fi, des d'Igualada (la capital comarcal) fins arribar a les immediacions de Calaf (dintre dels sectors corresponents a la denominada Alta Segarra o Segarra Calafina). 


\section{Objectius fonamentals}

Els objectius fonamentals que es pretenen aconseguir en aquest itinerari, es poden concretar en els següents aspectes generals:

1. Observació i descripció dels materials terciaris (exclusivament del Paleogen, i més concretament de l'Eocè i de I'Oligocè) de la Depressió Geològica de l'Ebre (i més exactament de la seva Depressió Central). Així, el recorregut de l'itinerari discorrerà inicialment entre els afloraments de la Formació Igualada i de la Formació Tossa (totes dues de l'Eocè i del Grup Santa Maria). Tot seguit es circularà entre els afloraments del Complex Lacustre d'Anoia (concretament per la Formació Artés, del trànsit de I'Eocè a I'Oligocè). Finalment s'arribarà als afloraments del Complex Lacustre de la Segarra (amb terrenys que ja pertanyen a la Formació Tàrrega, ja de l'Oligocè). Tots aquests terrenys constitueixen el subsòl dels diferents sectors, per entre els quals discorre el present itinerari. En part, es realitzarà un tall dels més profunds als més superiors.

2. Observació de les estructures locals de la Depressió Geològica de l'Ebre, al llarg del recorregut de l'itinerari; tot i això, no cal oblidar que el recorregut transitarà per una de les zones més estables de la depressió, alterada solament per alguns plecs relacionats amb els nivells de guixos.

3. Observació i reconeixement de les mineralitzacions evaporítiques guixoses situades pels voltants d'Igualada (els guixos d'Òdena de la Formació Tossa).

4. Observació de les explotacions relacionades amb els materials anteriors, com les següents, d'acord amb el sentit de la marxa de l'itinerari.

4A) Les explotacions dels materials guixosos, que trobarem a diversos indrets dels voltants d'Igualada, entre els nivells dels guixos d'Òdena de la Formació Tossa.

4B) de les explotacions dels materials carbonosos, que trobarem prop dels Prats de Rei, entre els materials de la Formació Tàrrega.

5. En tots els casos, a les explotacions anteriors, s'observaran les restauracions efectuades en elles, si s'escau.

6. S'observaran, al llarg de tot el recorregut, els diferents elements relacionats amb el Patrimoni Geològic i Miner- 


\section{Antecedents}

Pel que fa al recorregut del present itinerari, no existeixen gaires antecedents bibliogràfics, pel que fa a la totalitat del recorregut; ja que en bona part constitueix una primícia. Hi ha, però, alguns antecedents parcials, relatiu a algun dels trama inicials; entre aquests farem esment dels següents: Mata-Perelló (1997, 1999, 2000, 2001 i 2012).

Pel que fa a la descripció de les mineralitzacions, seguirem fent esment d'alguns altres treballs nostres: Mata-Perelló (1990 i 1991); el primer relatiu a la comarca de l'Anoia, el segon al conjunt de les mineralitzacions catalanes.

I, finalment, pel que fa a l'estructura geològica de la zona per la qual discorre l'itinerari, farem esment dels treballs de: Guimerà et altri (1982) i de Riba et altri (1976). També farem esment d’un treball nostre: Mata-Perelló (1985).

Tots aquests treballs referenciats, i d'altres, figuren esmentats per ordre alfabètic a l'apartat dedicat a la BIBLIOGRAFIA.

\section{Recorregut de l'itinerari}

El recorregut de l'itinerari discorrerà íntegrament per la comarca d'Anoia, des de principi a fi. Així, s'iniciarà a la capitat comarcal, al Barri de Fàtima de la ciutat d'Igualada, per on es faran les primeres aturades. I tot seguit, el recorregut es dirigirà cap a l'antiga carretera nacional $\mathrm{N}$ IIA, anant cap als sectors septentrionals d'Igualada, per tal d'agafar (per l'esquerra) la carretera C- 37, en seu tram vell. Així s'arribarà al Polígon Industrial de les Comes, prop d'on es farà una nova aturada.

Posteriorment, seguint per la vella $\mathrm{C}-37$ (anant cap a les immediacions d'Òdena) s'arribarà a I'Autovia A - 2, que caldrà agafar breument, fins arribar al trencall de la carretera local BV 1031, per la qual ens anirem dirigint cap al Nord, remuntant I'anomenada Serra de Rubió, fins dalt del tot, arribant al Parc Eòlic. En aquest tram, realitzarem diverses aturades.

Posteriorment, per aquesta mateixa carretera, ens continuarem adreçant cap al Nord, arribant fins prop de Sant Martí de Maçana. En aquest tram del recorregut, també farem diverses aturades. Després, ens adreçarem cap a la Manresana, per on farem una nova aturada. I, finalment, ens caldrà arribar fins a la població dels Prats de Rei, per on farem la darrera aturada d'aquest itinerari, finalitzant el mateix, camí de Calaf. 


\section{Advertiments previs}

Com en altres recorreguts de RECERCA GEOLÒGICA I MINERALÒGICA... si es disposa del temps suficient, poden efectuar-se passant per totes les parades i filloles. En cas contrari, recomanem prescindir de les anomenades PARADES - CONDICIONALS.

També cal tenir en conte que part del recorregut, tant a l'inici de l'itinerari, com als seus darrers trams, es realitzarà per camins de terra, per la qual cosa caldrà prendre les degudes precaucions. En aquest recorregut, caldrà fer un tram de poc més de $2 \mathrm{Km}$ en irregular estat de conservació, pels voltants de la Manresana.

Cal tenir, com sempre, una cura molt especial de respecte a la natura, al llarg de tot el recorregut de l'itinerari, i també fora d'ell.

\section{Descripció de l'itinerari}

Com de costum, estructurarem el recorregut de I'itinerari en una sèrie de PARADES, que anirem veient. En cadascuna d'aquestes aturades farem un breu comentari (geològic 0 mineralògic, segons s'escaigui). En cada cas indicarem, entre parèntesi, el full topogràfic on es troba l'aturada.

En aquest cas, el recorregut de l'itinerari s'inclourà dintre dels següents fulls, del "Mapa Topográfico Nacional", realitzats a l'escala 1:50.000 per l'I.G.C. de España": 362 (antigament dit de Calaf i ara de Sant Joan de Vilatorrada) i 391 (o d'Igualada). Tanmateix, si s'escau, es pot utilitzar el Mapa Topogràfic Comarcal d'Anoia, editat per I'Institut Cartogràfic de Catalunya.

Així doncs, la relació de les aturades, que composen el recorregut d'aquest itinerari és la següent:

\subsection{Parada 1. EXPLANADA D’ENTRADA AL BARRI DE FÀTIMA, (terme municipal d'Igualada, comarca de l'Anoia). (Full 391).}

El recorregut del present itinerari el començarem per les immediacions de la ciutat d'Igualada (la capital de la comarca d'Anoia). Els començarem a l'entrada del Barri de Fàtima, venint des de la carretera nacional $\mathrm{N}$ - IIA. Així, justament I'iniciarem en una explanada que es troba sobre una zona reomplerta del Torrent de Mas Arnau, molt prop de les instal-lacions esportives del barri.

Aquest indret es troba totalment situat dintre de la Depressió Geològica de l'Ebre (en concret dintre l'anomenada per nosaltres Depressió Central, MATA - PERELLÓ, 1985). Així, en aquest sector podem veure afloraments per tot arreu d'unes calcolutites gris blavoses, les que formen part de I'anomenada Formació Igualada. Es tracta de nivells d'origen marí, amb presència majoritària de calcolutites i més minoritària de gresos, també de tonalitats gris - blavoses. (fotografia 1). 


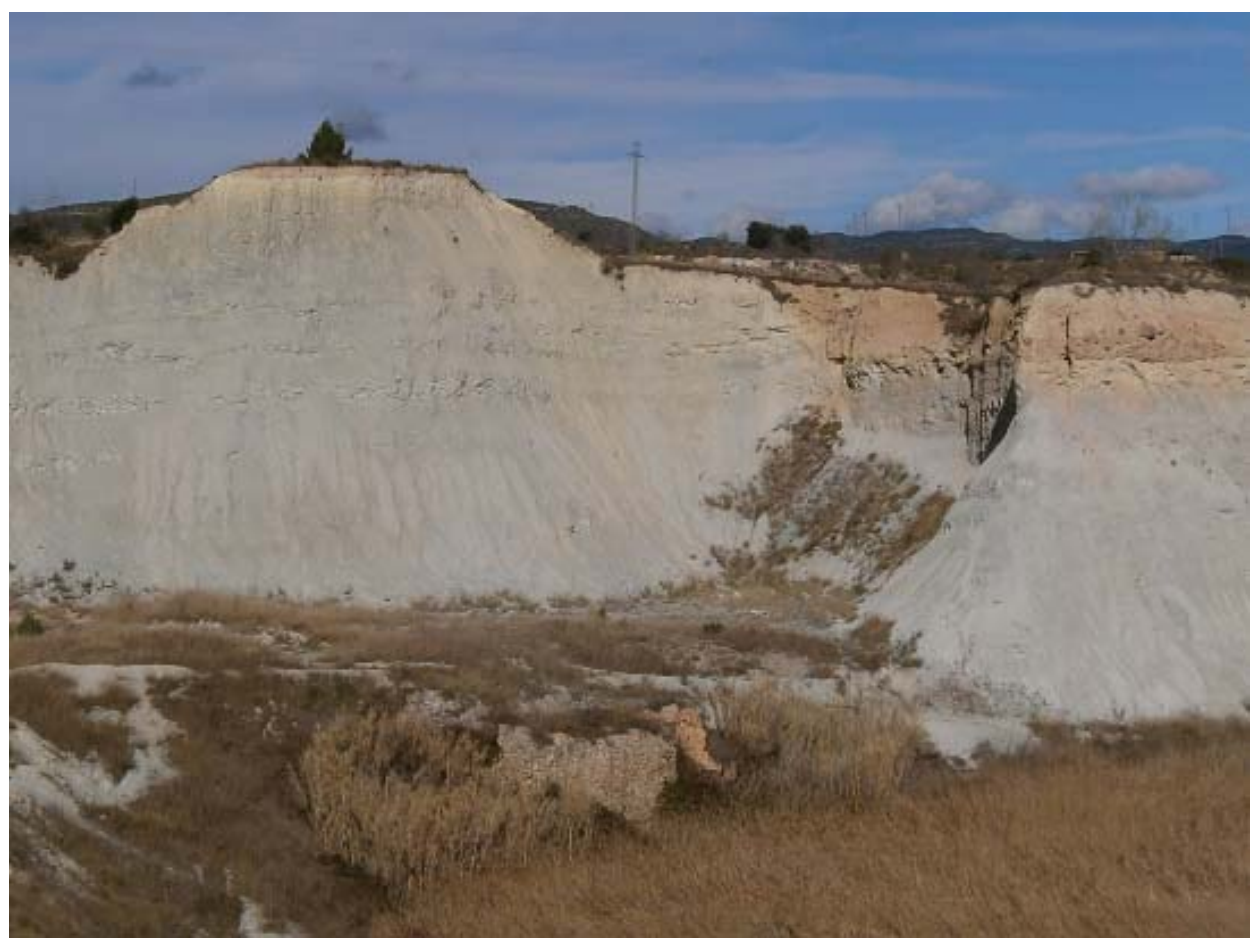

Fotografia 1. Aflorament de les calcolutites gris - blavoses de la Formació Igualada. Torrent de Mas Arnau A la part superior de la fotografia, es pot veure una discordança amb terrenys detrítics del Pleistocè

Observant aquests materials eocènics, es poden veure interessants aixaragallaments per diferents indrets.

Per d'altra banda, en aquest indret es pot veure com el Torrent de Mas Arnau va ésser canalitzat, al seu pas per bona part del Barri de Fàtima, per sota d'on estem ara situats.

\subsection{Parada 2 - CONDICIONAL. ANTIC FORN D’OBRA DEL TORRENT DE MAS ARNAU, (terme municipal d'Igualada, comarca de l'Anoia). (Full 391).}

Després de realitzar la parada anterior, hi ha possibilitat de baixar fins al torrent, per tal de fer una nova aturada, si s'escau. En aquest cas, haurem de recórrer uns 200 metres, que serà molt millor de fer-ho a peu. En arribar baix, farem aquesta nova aturada.

En aquest breu recorregut, hem continuat trobant els materials esmentats a l'aturada anterior. Aquests terrenys de la Formació Igualada, son també els que apareixen a l'indret de l'aturada.

En aquest lloc hi ha res restes d'un antic Forn d'Obra (o Forn de Teules) el qual es troba enormement trinxat i cobert de vegetació. Amb dificultats es pot veure com era un doble forn, que aprofitava els materials argilosos de les proximitats. (fotografia 2). 


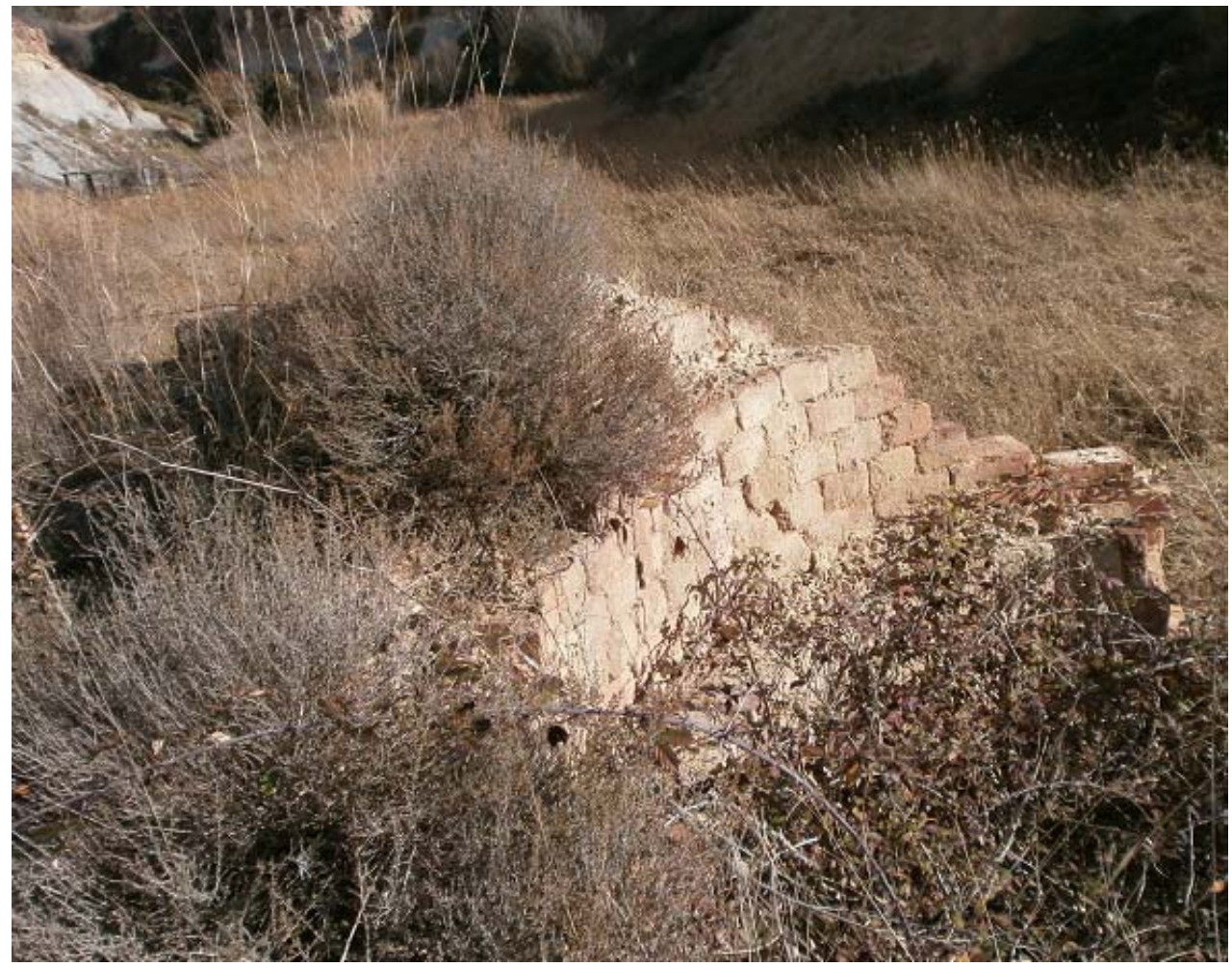

Fotografia 2. Tot i el seu lamentable estat de conservació, aquest forn forma part del Patrimoni Miner de la Comarca d'Anoia. I creiem que caldria fer feines de desbrossament, per tal de conèixer el seu valor real i el seu estat amb més precisió.

Per altra banda, des d'aquest indret, es pot veure l'embocadura de la canalització del Torrent de Mas Arnau, tot mirant cap al Sud d'on ara estem situats.

\subsection{Parada 3 - CONDICIONAL. ANTIGUES GUIXERES DEL POLÍGON INDUSTRIAL DE LES COMES, (actualment del terme municipal d'Igualada i antigament del d'Òdena, comarca de I’Anoia). (Full 391)}

Després de fer la parada anterior, cal sortir del barri, per tal d'anar cap a la carretera nacional $\mathrm{N}$ - IIA. En trobar-la ens dirigirem cap a llevant, arribant a la seva travessia dels sectors septentrionals de la ciutat d'Igualada, on ara ens trobem situats. En arribar a les immediacions del Polígon Industrial de les Comes, ens hi caldrà anar-hi, utilitzant el tram antic de la carretera autonòmica $\mathrm{C}-37$ (en el seu sentit cap a Òdena i cap a Manresa). Pel bell mig del polígon, trobarem carrers industrials que es dirigeixen cap al Nord. Ens caldrà agafar un d'aquests vials. Així arribarem a un turó que es troba farcit d'antigues explotacions de guix. Aquí farem una nova aturada, a uns $2^{\prime} 5 \mathrm{Km}$ de l'anterior. Cal dir que aquest indret ara pertany al terme d'Igualada, que el va adquirir al terme veí d’Òdena, per tal de posar-hi aquí el polígon industrial, ja que el terme d'Igualada és un dels més petits de Catalunya. 
En aquest recorregut, hem continuat trobant els materials esmentats a les aturades anteriors; és a dir les margues gris - blavoses de la Formació Igualada. Tot i així, a l'indret de la present aturada, apareixen uns nivells de guixos; es tracta dels coneguts com a guixos d'Òdena.

Aquests materials han estat explotats a diferents indrets del turó on estem ara situats. També han estat explotats (i en part encara ara ho estan), a la veïna població d'Òdena. Des d'aquí ben visible. (fotografia 3 ).

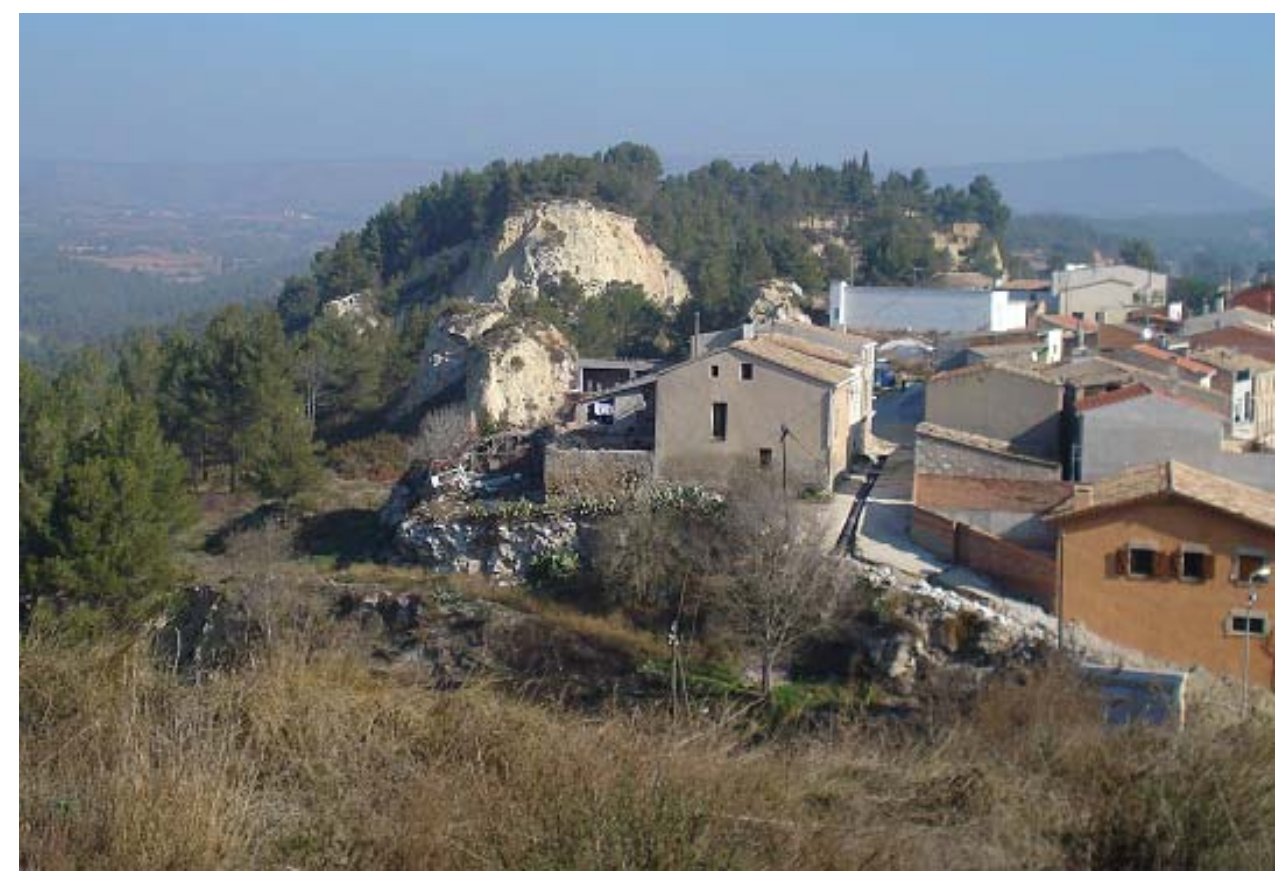

Fotografia 3. Explotacions dels guixos d'Òdena, a la propera població d'Òdena

\subsection{Parada 4. IMMEDIACIONS DEL Km 13’5, DE LA CARRETERA BV - 1031, (terme municipal d'Òdena, comarca de l'Anoia). (Full 391).}

Després de realitzar la parada anterior, cal tornar al tram antic de la carretera $C-37$, que travessa el Polígon Industrial de les Comes. Seguint aquesta carretera, en el seu sentit cap a Òdena, arribarem fàcilment a I'Autovia $A-2$. En trobar-la, ens caldrà agafar-la en el seu sentit ponentí. Però molt aviat trobarem la sortida cap a la carretera local BV 1031. Aquesta carretera es dirigeix cap als Prats de Rei. En agafar-la, ens dirigirem cap el Nord, començant a pujar cap a la propera Serra de Rubió. En arribar a les immediacions del Km 13 d'aquesta carretera, farem una nova aturada. Així, des de la parada anterior, haurem recorregut uns $8 \mathrm{Km}$, aproximadament, per tal d'arribar a aquest indret, prop de les runes d'una antiga casa, a la dreta del barranc i de la carretera (Can Tesanet).

En aquest recorregut, en apropar-nos al Torrent d'Òdena, haurem tornat a trobar els afloraments de les calcolutites gris - blavoses de la Formació Igualada. Després, per sobre d'elles, haurem tornat a trobar els nivells blanquinosos dels guixos d'Òdena (de la Formació Tossa). I per sobre, haurem començat a veure els nivells rogencs dels gresos i calcolutites de la Formació Artés (del Complex Al.luvial de l'Anoia). Aquests són els materials que apareixen ara, pels indrets de la present aturada; i també des de la sortida d'Igualada cap el Nord, pràcticament. 
Per d'altra banda, en aquest recorregut, mirant cap al Nord, cap a la propera Serra de Rubió, que es troba davant nostre, haurem vist un conjunt de típics relieves en cuesta. Aquests venen determinats per la presència de nivells més durs entre els materials de la Formació Artés. Així, ara des d'aquest indret, es pot veure un d'aquests nivells, que constitueixen el primer esgraó. (fotografia 4).

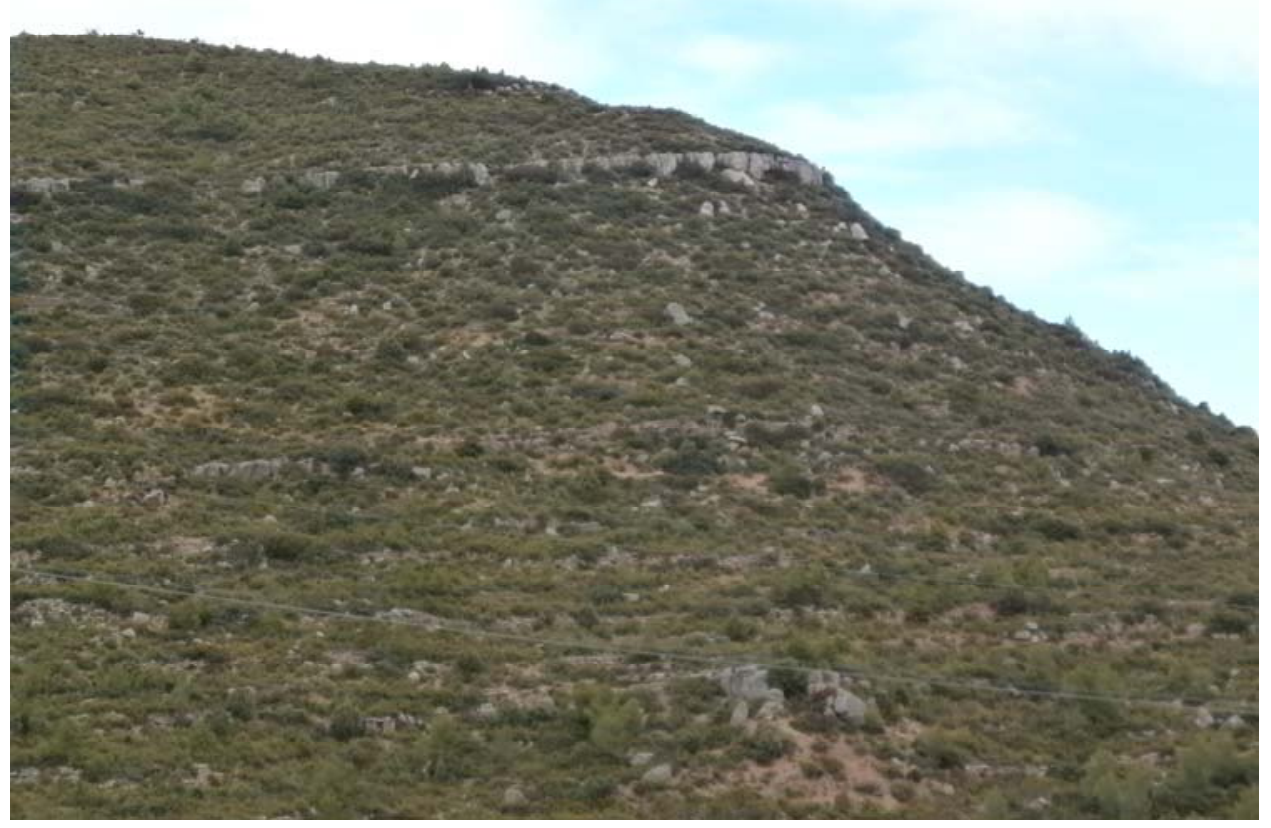

Fotografia 4. Un aspecte del primer esgraó dels relieves en cuesta de la Serra de Rubió. Sobre d'ell es situa el Pla de Servitje, prop d'on ara som

\subsection{Parada 5. LES MALLOLES, (terme municipal d'Òdena, comarca de l'Anoia). (Full 391).}

Després d'efectuar la parada anterior, cal continuar cap el Nord per la carretera local BV 1031. Per ella, aviat arribarem a les Malloles, per on la carretera comença a fer una sèrie de corbes. En aquest indret, abans de començar a pujar, farem una nova aturada, a uns $2 \mathrm{Km}$ de la darrera aturada efectuada.

En aquest recorregut, hem continuat trobant els materials abans esmentats de la Formació Artés. Així, haurem trobat nivells de calcolutites i de gresos rogencs, continentals (aquests materials tenen presencia d'HEMATITES, el qual dona el color rogenc als materials). Per d'altra banda, molt sovint haurem trobat nivells més detrítics, tot formant part de paleocanals.

Tot i així, en aquest indret es fan palesos uns nivells de tonalitats més blanquinoses. Es tracta d'uns materials carbonatats i sovint també calcolutítics. (fotografia 6). 


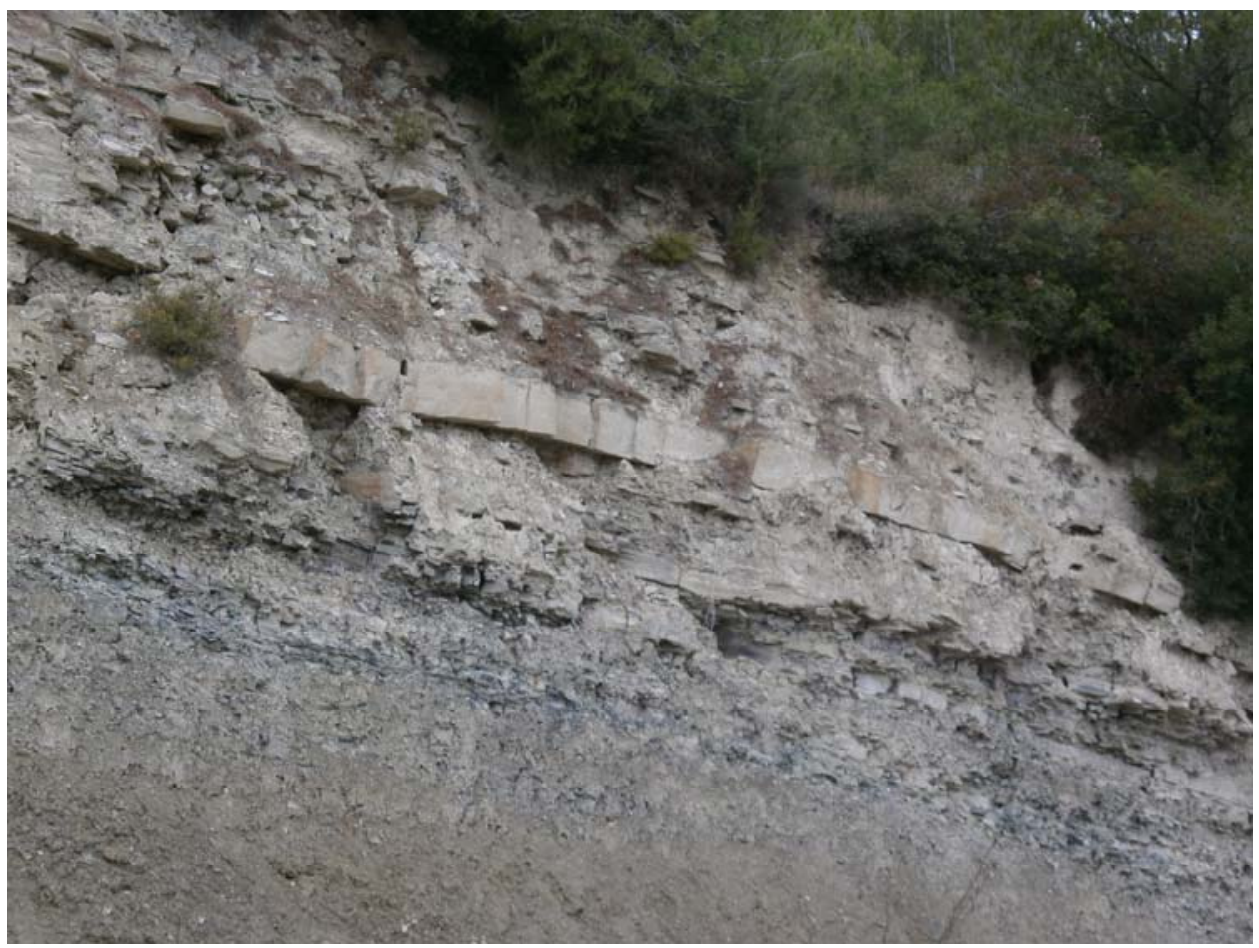

Fotografia 5. Els materials blanquinosos de les Malloles.

Aquests materials són, precisament els que hem vist a l'aturada anterior, formant l'esgraó. Aquí, sobre aquest esgraó es troba la casa de les Malloles. Per d'altra banda, cap a ponent, aquests materials tenen un canvi lateral de fàcies, passant a constituir en molts indrets els guixos de Clariana, com prop d'on ara som; concretament al Pla de Rubió, entre altres indrets.

\subsection{Parada 6. TRENCALL DE RUBIÓ, SERRA DE RUBIÓ, (terme municipal d' Òdena, comarca de l'Anoia). (Full 391)}

Després de fer la parada anterior, cal continuar cap amunt per la carretera local BV - 1031, la qual es va adreçant cap a la Serra de Rubió. Precisament, després de fer l'aturada anterior, ens trobarem un conjunt de revolts. Així, anirem pujant cap a la part més alta de la serra abans esmentada. En arribar dalt, al trencall d'on eix una carretereta cap al poble de Rubió, farem una nova aturada, al costat d'uns aerogeneradors. Així, des de la parada anterior, haurem recorregut uns $3 \mathrm{Km}$ més.

En aquest recorregut, hem anat trobant els materials que hem esmentat a l'aturada anterior. Aquests materials formen part de la Formació Artés; tot i que ara es fan molt palesos els nivells de conglomerats, tot constituint paleocanals, de vegades molt potents. Aquests nivells són els que configuren la part alta de la Serra de Rubió, constituint l'esgraó més alt del conjunt de relieves en cuesta, que configurem aquesta serra.

Per d'altra banda, cal dir que després de sobrepassar el primer esgraó, s'han fet paleses unes petites planes, que cap a llevant i cap a ponent són més ben definides, on constitueixen, respectivament el Pla de Servitje i el Pla de Rubió. 
Per d'altra banda, a aquest indret tenim un bon lloc d'observació de la part meridional de la comarca d'Anoia. Així, cap el centre es fa palesa la denominada Conca d'Òdena, per on afloren els materials eocènics que hem vist abans, pels voltants de la ciutat d'Igualada. Més cap el Sud, es fan presents els relleus de la Serralada Prelitoral (on afloren els materials paleozoics de I'Ordovicià i el mesozoics del Triàsic). Tanmateix es pot veure com el riu Anoia travessa aquesta serralada, a través del Congost de Capellades. (fotografia 6).

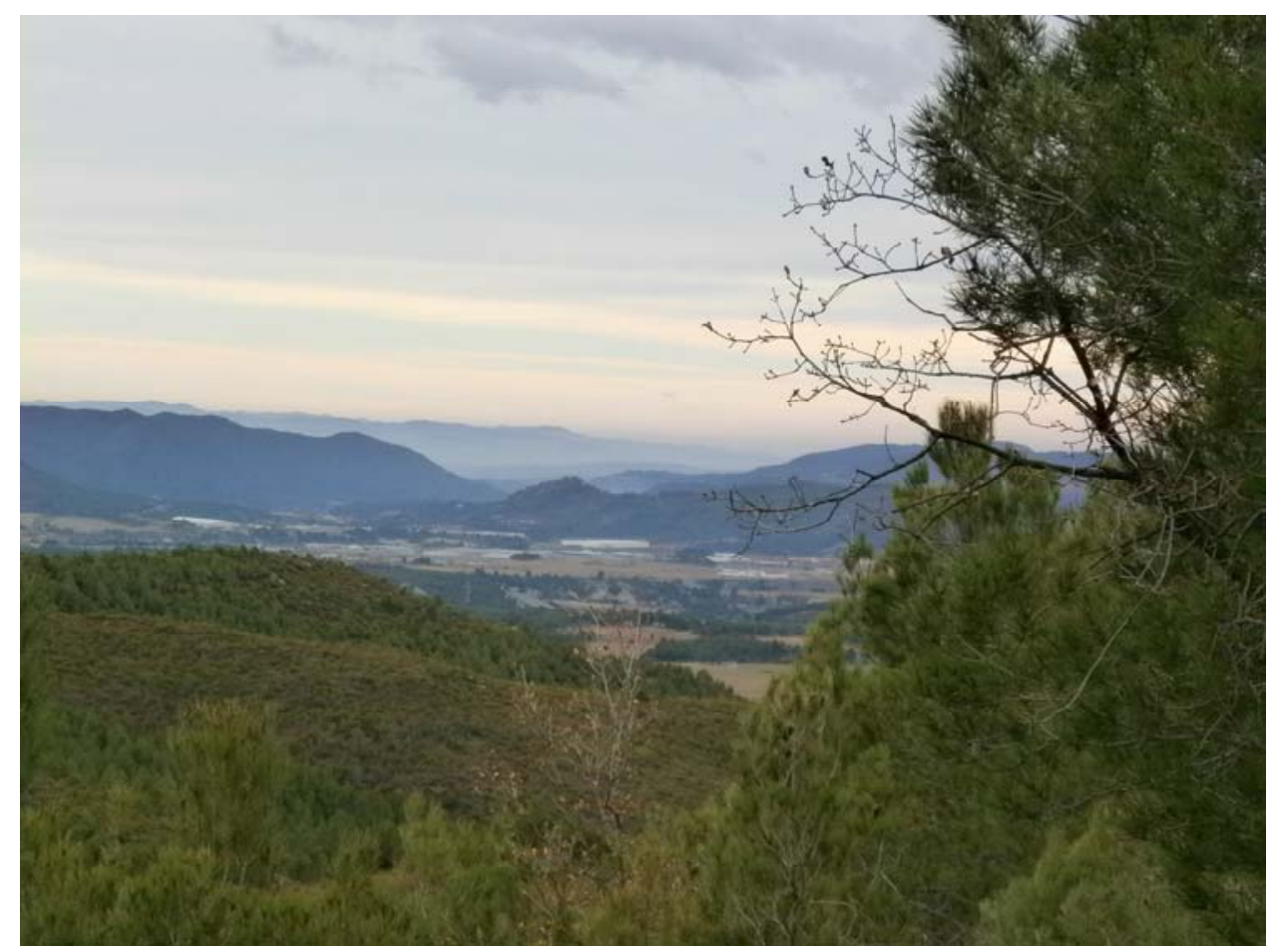

Fotografia 6. La Conca d'Òdena, des de les immediacions del Trencall de Rubió, Carretera BV - 1031

Cap el centre es veuen els materials eocènics que formen la Conca d'Òdena, pels voltants d'Igualada. Al centre es veu el relleu del Castell de la Pobla de Claramunt. Més lluny es veu la vall del riu Anoia travessant la Serralada Prelitoral. I més lluny s'endevina la Depressió Prelitoral i la Serralada Litoral a I’Horitzó 


\subsection{Parada 7 - CONDICIONAL. IMMEDIACIONS DEL TRENCALL DE CASTELLFOLLIT DEL BOIX, (terme municipal d'Òdena, comarca de l'Anoia). (Full 391)}

Després de fer la parada anterior, cal fer un breu recorregut per la carretera local que anem seguint cap el Nord, cap als Prats de Rei. A poc menys de 0 '5 Km del trencall de Rubió, en trobarem un altre (ara per la dreta), des d'on surt un vial inicialment asfaltat. Aquest vial condueix cap a Castellfollit del Boix, entre altres indrets. Poc abans d'arribar al trencall, podem fer una nova aturada, si s'escau.

En aquest breu recorregut, hem anat trobant els materials esmentats a l'aturada anterior; tot $\mathrm{i}$ que cada vegada es fan més palesos els nivells dels conglomerats dels paleocanals. Efectivament, ara estem arribant als indrets més alts de la Serra de Rubió i també a l'esgraó més alt. Aquest es troba constituït per aquets marials eminentment detrítics. Aquets materials i els paleocanals, els podem veure a la (fotografia 7 ).

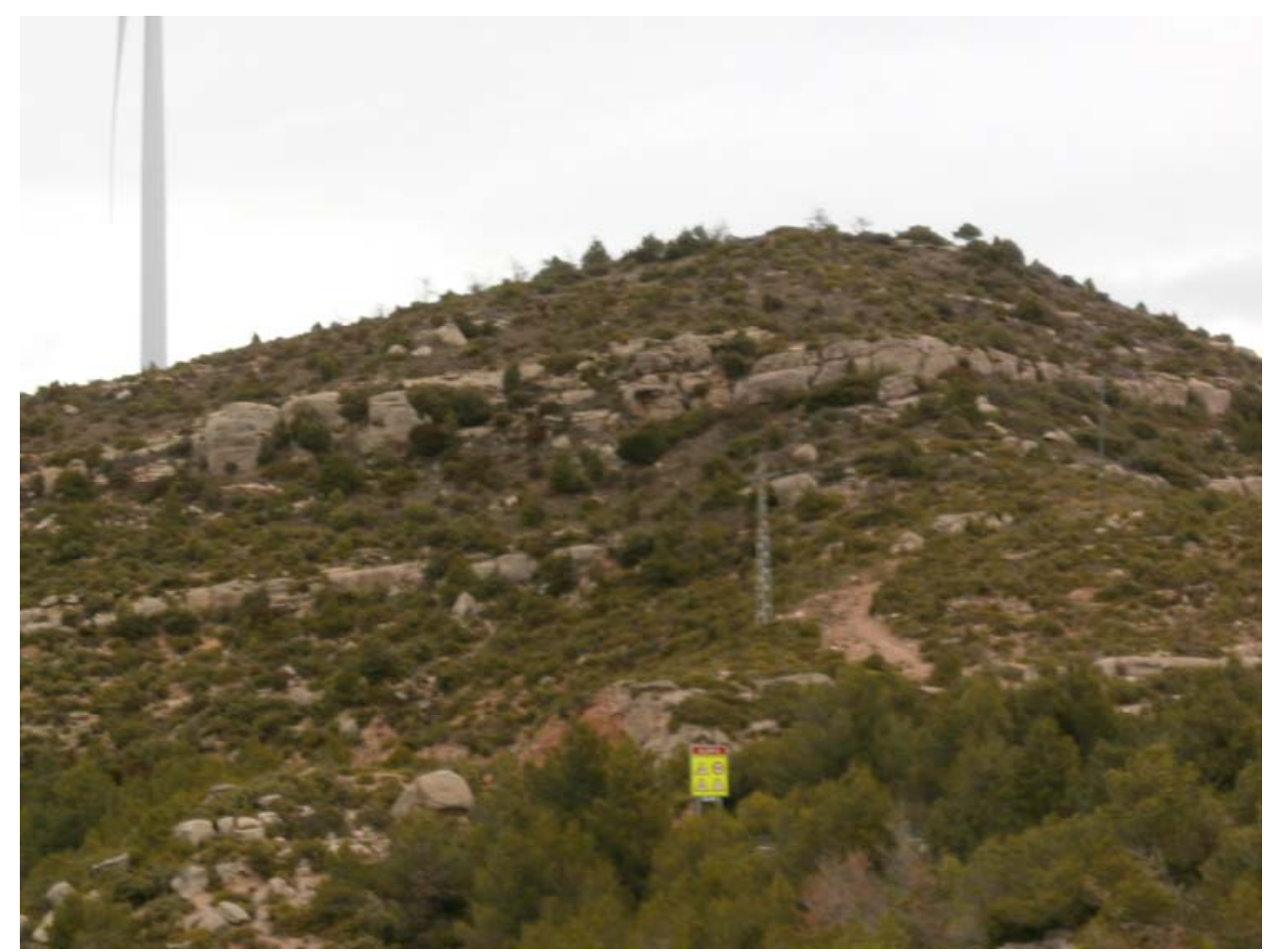

Fotografia 7. Detall dels paleocanals (i dels nivells detrítics que els constitueixen) a les parts més altes de la Serra de Rubió. Prop del trencall de Castellfollit del Boix 


\subsection{Parada 8. SEPULCRE MEGALÍTIC DE LES IMMEDIACIONS DEL Km 7’5, CARRETERA BV - 1031, (Sant Martí de Maçana, terme municipal de Rubió, comarca d'Anoia). (Full 362).}

Després d'efectuar l'anterior aturada, cal continuar per la carretera local BV - 1031, la qual es va dirigint cap el Nord, apropant-nos cada vegada més cap el poble de l'Alta Segarra dels Prats del Rei. En arribar a les immediacions del Km 7’5, podem fer una nova aturada. Així, des de I'anterior, haurem efectuat un recorregut molt proer a $1^{\prime} 2 \mathrm{~km}$, per tal d'arribar fins aquest indret on ara som.

En aquest recorregut, s'han continuat fent palesos els afloraments dels materials de la Formació Artés. Com en tot el recorregut, presenten tonalitats eminentment rogenques, com a la presència de l'òxid de ferro (HEMATITES), on el ferro es troba oxidat en forma de Fe amb valència 3. Aquest mineral tenyeix als altres integrants de les roques (CALCITA, CAOLINITA, QUARS, entre altres) de tonalitats blanques o incolores. Així, haurem trobat nivells de calcolutites i de gresos rogencs, fonamentalment. També haurem trobat roques detrítiques, com conglomerats, les quals formen part dels nombrosos paleocanals.

En aquest indret, hi ha un sepulcre megalític, que pot ser força interessant d'observar. (fotografia 8).

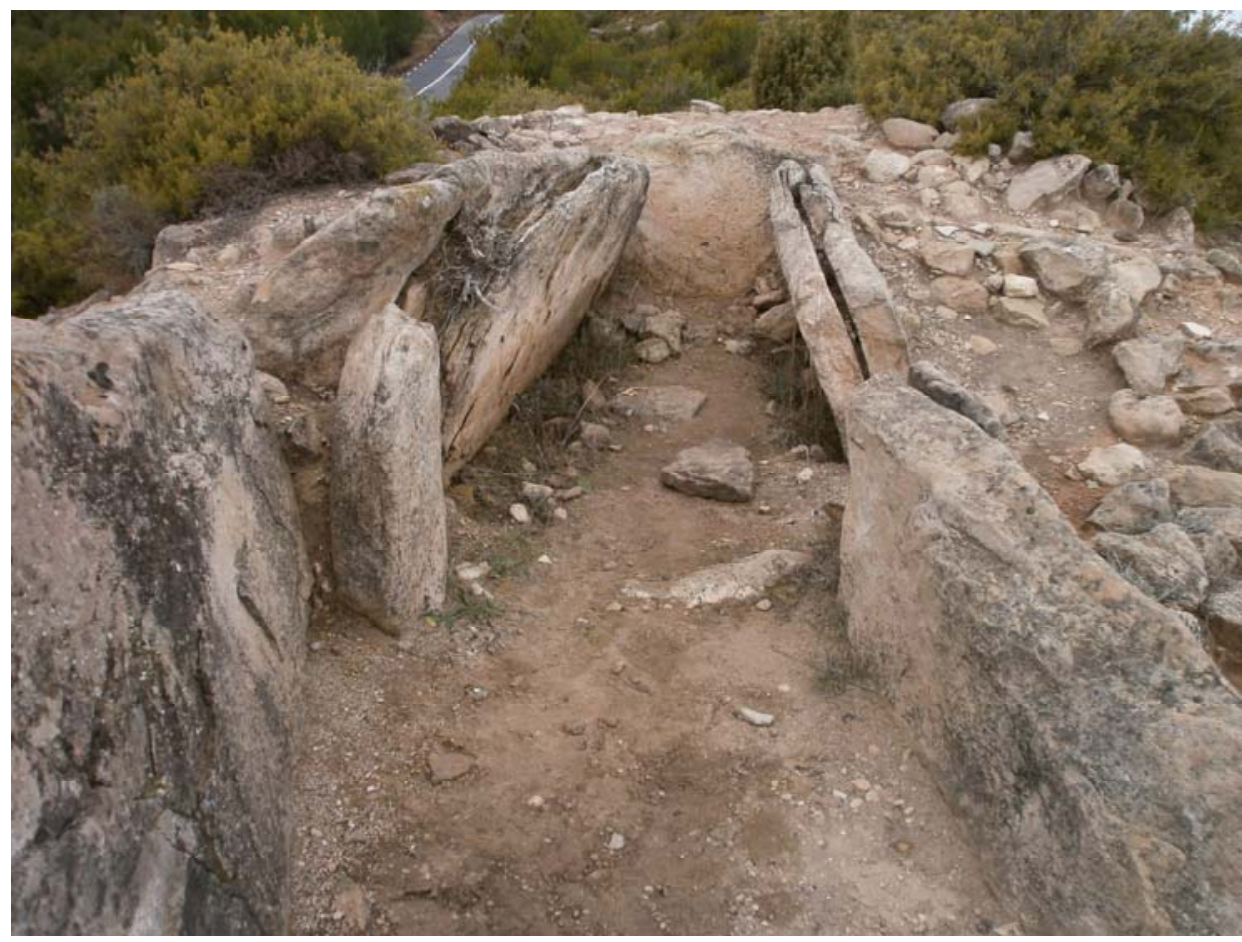

Fotografia 8. Aspecte del Sepulcre Megalític. Immediacions del Km 7 de la carretera BV - 1031 
En veure'l es poden observar les lloses laterals constituïdes per gresos de la Formació Artés. També es pot veure el substrat rogenc per arreu.

Al respecte d'aquest sepulcre megalític, cal dir que no és pas l'únic que hi ha per aquestes contrades. Efectivament, una mica més avall, prop del $\mathrm{Km} 5$ de la carretera, $\mathrm{n}$ 'hi ha un altre d'assenyalat. Precisament, en aquet indret, mirant cap el NNW es pot gaudir d'una certa visió del Sinclinal de Calaf, que també es pot interpretar des de la següent aturada. Ara, des d'aquí es pot veure aquesta visió: (fotografia 9).

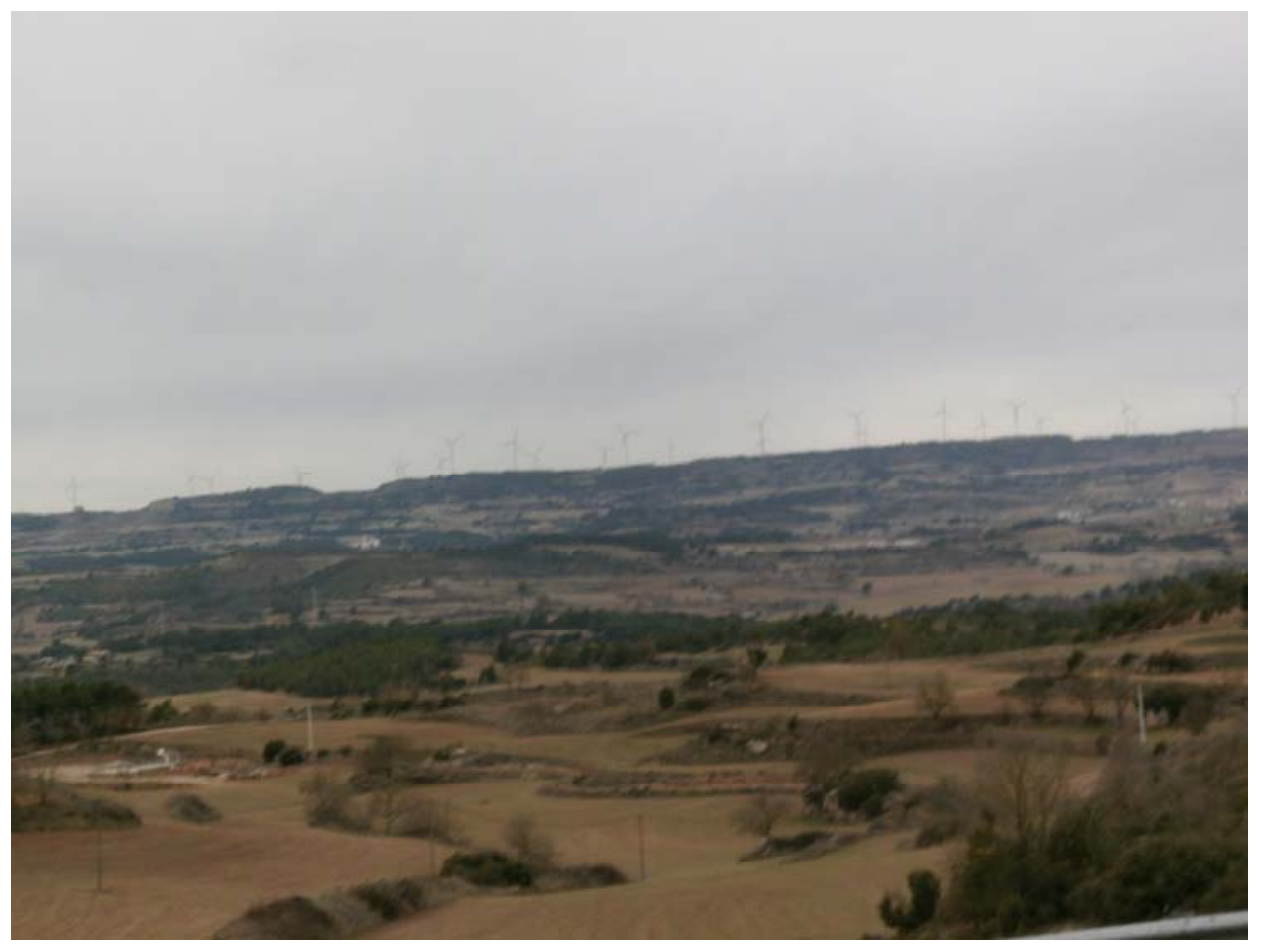

Fotografia 9. Una visió llunyana del Sinclinal de Calaf, des de les immediacions del Km 5 de la BV - 1031

\subsection{Parada 9. IMMEDIACIONS DE LA MANRESANA, (la Manresana, terme municipal dels Prats de Rei, comarca d'Anoia, subcomarca de l'Alta Segarra). (Full 390).}

Després de realitzar I'anterior aturada, cal fer un altre recorregut per la carretera local BV 1031, apropant-nos cada vegada més cap als Prats de Rei. Aviat, a poc menys de 0’5 Km de la parada anterior, trobarem el trencall que es dirigeix cap a Sant Martí de Maçana. Poc després, a 1'5 Km, trobarem el trencall que es dirigeix cap a la Manresana, cap on anirem. En arribar-hi, farem una nova aturada, a uns $4 \mathrm{Km}$ i escaig de la parada anteriorment realitzada.

En aquest recorregut, hem tornat a trobar afloraments dels materials ja esmentats a l'aturada anterior. Tot i això, cada vegada es fan paleses intercalacions de calcolutites grisenques. Efectivament, estem passant de la Formació Artés cap a la Formació Tàrrega.

En aquest indret hi ha una interessant torre de guaita (una típica Torre Manresana), que va ésser escenari d'una victòria austriacista sobre els borbons a la guerra de successió. 


\subsection{Parada 10 - CONDICIONAL. MINA DE LIGNIT DELS PRATS DE REI, (terme municipal dels Prats de Rei, comarca de l'Anoia, subcomarca de I'Alta Segarra). (Full 390).}

Una vegada realitzada l'aturada anterior, cal anar ja cap a la propera població dels Prats de Rei. Per tal d'anar-hi hi ha la possibilitat de retornar cap a la carretera local BV - 1031 i anar directament cap el poble. Tanmateix hi ha la possibilitat d'anar cap a la carretera autonòmica $C$ - 1412A (cap el ponent de la Manresana), per tal d'anar després cap al proper poble bans esmentat. Després, des dels Prats de Rei, caldrà remuntar el riu Anoia, pel seu cantó dret. A uns $1^{\prime} 5 \mathrm{Km}$ del poble trobarem l'escombrera d'una antiga mina de lignit. Aquí farem la darrera aturada d'aquest itinerari. Així, des de la parada anterior haurem recorregut uns $4 \mathrm{Km}$ més.

En aquest recorregut, hem anat trobant afloraments dels nivells de calcolutites grisenques i de nivells carbonatats. Aquests materials formen part de la Formació Tàrrega i es situen dintre del Complex Al.luvial de la Segarra. Per d'altra banda, aquests materials presenten un clar cabussament cap el Nord i formen part del flanc meridional del Sinclinal de Calaf, on estem ara situats.

En aquest indret hi havia una antiga mina de lignit. Aquests lignits es situen dintre dels materials de la Formació Tàrrega. Es tracta d'uns lignits molt pobres i alhora molt ferruginosos. Així es fàcil veure mineralitzacions secundàries de ferro, amb presència de GOETHITA (en forma de LIMONITA) i de MELANTERITA. També és fàcil veure GUX, que s'ha format com a conseqüència de l'atac de l'Àcid Sulfúric (originat per l'alteració de la PIRITA primària) sobre la CALCITA, present entre les calcolutites.

Pel que fa a la mina, cal dir que no va ésser gaire important. Formava part de la Conca lignitífera de Calaf. Ara sols es pot veure l'escombrera. (fotografia 10).

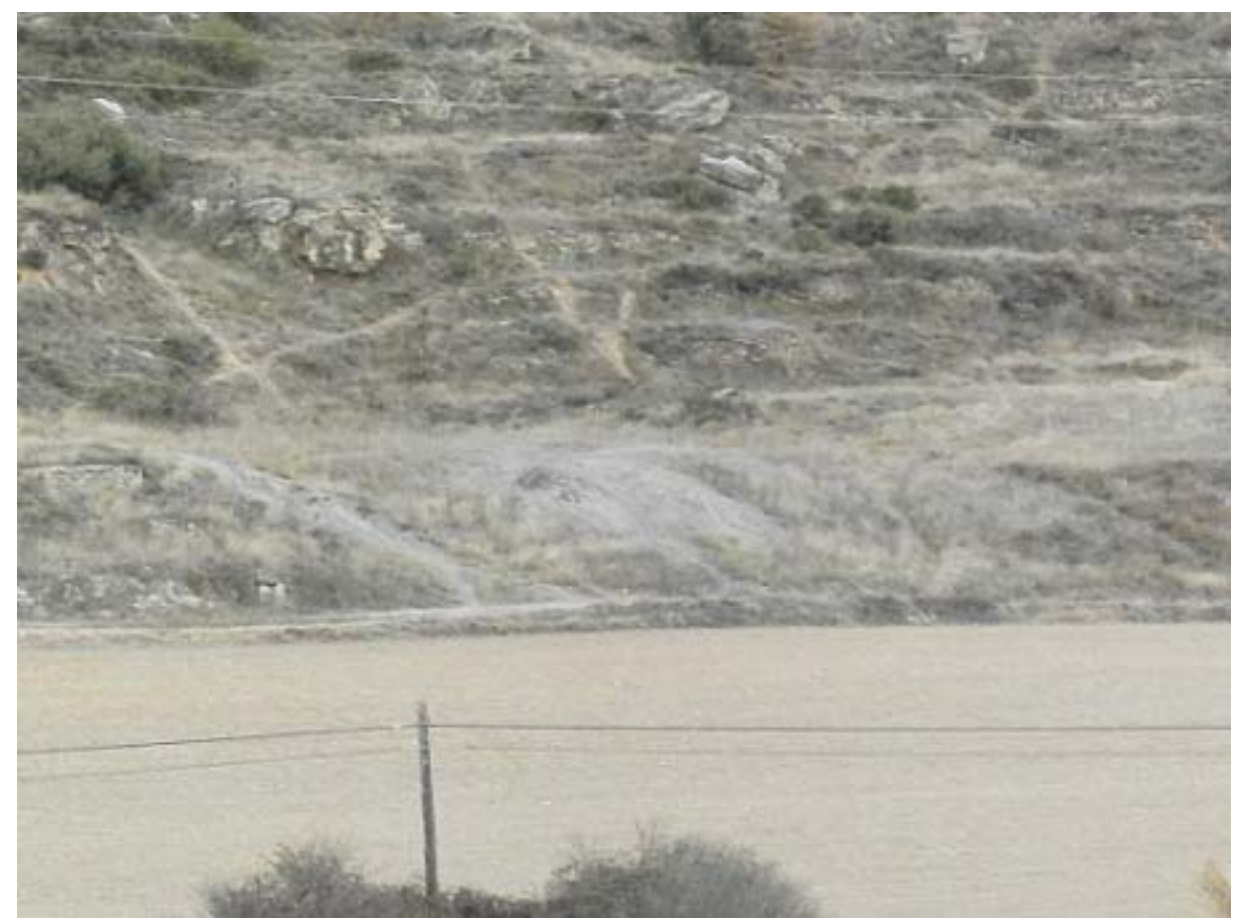

Fotografia 10. Al centre de la fotografia, encara es poden veure les restes de l'escombrera de la mina de lignit dels Prats de Rei 
En aquest indret finalitza el recorregut de l'itinerari.

\section{Bibliografia}

GUIMERÀ, J. et altri (1992).- Geologia (II), Història Natural dels Països Catalans, Vol.2, 547 pag. Enciclopèdia Catalana, S.A. Barcelona.

MATA - PERELLÓ, J.M. (1985).- Depressió de l'Ebre ?, Depressió Central ?. Revista Dovella, $\mathrm{n}^{\circ} 15$, pp.. $45-48$. Manresa.

MATA-PERELLÓ, J.M. (1990).- Inventari Mineralògic de la comarca d'Anoia. Revista Xaragall, $\mathrm{n}^{\circ} 24,40$ pag. Manresa.

MATA-PERELLÓ, J.M. (1991).- Els Minerals de Catalunya. Arxius de la Secció de Ciències, t. XCIII, 442 pag. Institut d'Estudis Catalans. Barcelona.

MATA-PERELLÓ, J.M. (1997).- Recerca geològica i mineralògica per les guixeres de la comarca d'Anoia: des d'Ödena i l'Espelt a Jorba i a Clariana. Inèdit, 11 pag. Manresa.

MATA-PERELLÓ, J.M. (1999).- Recerca geològica i mineralògica per la comarca d'Anoia: des d'Òdena i l'Espelt a Jorba, i des de Clariana i Argençola a Bellmunt i Aguiló. Inèdit, 10 pag. Manresa.

MATA-PERELLÓ, J.M. (2000).- Recerca geològica i de reconeixement dels georrecursos per les pedreres de la comarca d'Anoia: des d'Òdena i l'Espelt a Sant Martí de Tous, i des de Clarianai i Argençola a Carbassí. Algeps, sèrie B, nº 172, 11 pag. Manresa.

MATA-PERELLÓ, J. M. (2001).- Recerca geològica i geoambiental per les comarques d'Anoia i de la Segarra: des d'Òdena i l'Espelt cap a Sant Genís i Jorba, i des de Montmaneu a Sant Pere dels Arquells. Inèdit, 8 pàgines. Manresa.

MATA-PERELLÓ, J. M. (2012).- Recorregut de recerca geològica i geoambiental per les comarques del Bages, d'Anoía i de la Segarra: des de Maians i Òdena cap a Jorba, la Panadella i a Sant Pere dels Arquells. Inèdit. 14 pàgines. Manresa.

RIBA, O. et altri (1976).- Geografia Física dels Països Catalans, Edit. Ketres, 254 pàgines. Barcelona. 